\title{
Thyroid function in multidrug-resistant tuberculosis patients with or without human immunodeficiency virus (HIV) infection before commencement of MDR-TB drug regimen.
}

\author{
Olusoji Mayowa Ige ${ }^{1}$, Kehinde Sola Akinlade ${ }^{2}$, Sheu Kadiri Rahamon², Victory Fabian Edem², \\ Olatunbosun Ganiyu Arinola²
}

1. Department of Medicine, University of Ibadan/University College Hospital, Ibadan, Nigeria.

2. Deaprtment of Chemical Pathology, University of Ibadan/University College Hospital, Ibadan, Nigeria.

\begin{abstract}
Background: Mycobacterium tuberculosis and human immunodeficiency virus (HIV) are known to cause abnormal thyroid function. There is little information on whether HIV infection aggravates alteration of thyroid function in patients with MDRTB.

Objectives: This study was carried out to determine if HIV co-infection alters serum levels of thyroid hormones (T3, T4) and thyroid stimulating hormone (TSH) in patients with MDR-TB patients and to find out the frequency of subclinical thyroid dysfunction before the commencement of MDR-TB therapy.

Methods: This observational and cross-sectional study involved all the newly admitted patients in MDR-TB Referral Centre, University College Hospital, Ibadan, Nigeria between July 2010 and December 2014. Serum levels of thyroid stimulating hormone (TSH), free thyroxine (fT4) and free triiodothyronine (fT3) were determined using ELISA.

Results: Enrolled were 115 patients with MDR-TB, out of which $22(19.13 \%)$ had MDR-TB/HIV co-infection. Sick euthyroid syndrome (SES), subclinical hypothyroidism and subclinical hyperthyroidism were observed in 5 (4.35\%), $9(7.83 \%)$ and $2(1.74 \%)$ patients respectively. The median level of TSH was insignificantly higher while the median levels of T3 and T4 were insignificantly lower in patients with MDR-TB/HIV co-infection compared with patients with MDRT-TB only.

Conclusion: It could be concluded from this study that patients with MDR-TB/HIV co-infection have a similar thyroid function as patients having MDR-TB without HIV infection before commencement of MDR-TB drug regimen. Also, there is a possibility of subclinical thyroid dysfunction in patients with MDR-TB/HIV co-infection even, before the commencement of MDR-TB therapy.
\end{abstract}

Keywords: HIV, multidrug-resistant TB, subclinical thyroid dysfunction, thyroid hormones.

DOI: http://dx.doi.org/10.4314/ahs.v16i2.30

Cite as: Ige OM, Akinlade KS, Rahamon SK, Edem VF, Arinola OG. Thyroid function in multidrug-resistant tuberculosis patients with or without human immunodeficiency virus (HIV) infection before commencement of MDR-TB drug regimen. Afri Health Sci 2016;16(2): 596-602. bttp://dx.doi.org/10.4314/abs.v16i2.30

\section{Introduction}

Multidrug-resistant tuberculosis (MDR-TB) continues to be a public health problem because of its increasing trend $^{1,2}$. Due to the ineffectiveness of two most effective anti-TB drugs (isoniazid and rifampicin), treatment of MDR-TB becomes challenging as it involves combination of a minimum of 5 drugs for at least 20 months ${ }^{3,4}$. Management of MDR-TB is daunting especially, when
Corresponding author:
Olatunbosun Ganiyu Arinola,
Deaprtment of Chemical Pathology,
University of Ibadan/University
College Hospital, Ibadan, Nigeria.
Tel: +2348023451520
Email: drarinolaog64@yahoo.com

it co-exists with HIV infection. It has been shown that management of MDR-TB or MDR-TB with HIV coinfection is associated with some adverse events such as alteration in thyroid hormone levels ${ }^{4,5,6}$. Thus, the need to determine the status of thyroid hormones before the commencement of therapy cannot be over emphasized. The thyroid gland plays an important role in the maintenance of body metabolism. Principally, it secretes thyroxine (T4) and triiodothyronine (T3) under the influence of thyroid stimulating hormones ${ }^{7,8}$. Reports have shown that there is alteration in thyroid hormone levels in patients with non-thyroid illnesses such as TB. This alteration has been attributed to anti-TB drugs especially, the secondline anti-TB drugs which cause more adverse effects than the first-line anti-TB drugs used for the treatment of drug-sensitive $\mathrm{TB}^{9}$. The exact mechanism responsible 
for the alteration is still unknown ${ }^{8,10}$, though the following mechanisms were suggested; viz: decreased T4 to T3 conversion, decreased TSH production and action of drugs such as ethionamide and prothionamide used for the treatment of MDR-TB on the thyroid causing hypothyroidism by inhibiting thyroid hormone synthesis through inhibition of iodine organification ${ }^{11-13}$. Similarly, antiretroviral therapies such as stavudine, amprenavir and lopinavir have been associated with hypothyroidism ${ }^{14,15}$. It is therefore important to assess thyroid function test before commencement of MDR drug regimen.

Although WHO guidelines recommended that TSH level should be monitored in patients with MDR-TB at least every 6 months ${ }^{12}$, there is lack of information on whether HIV infection has an additional effect on the alteration of thyroid hormones in patients with MDR-TB. Information on thyroid hormone status of MDR-TB patients will identify MDR-TB patients with subclinical thyroid dysfunction who might benefit from appropriate clinical intervention before the commencement of MDRTB drug regimen which could get worse with the commencement of the therapy. To provide information on thyroid function in Nigerian MDR-TB patients with HIV co-infection, we determined the serum levels of thyroid hormones in patients with MDR-TB and MDR-TB/HIV co-infection.

\section{Methods \\ Subjects}

This observational and cross-sectional study involved all the MDR-TB patients admitted at the MDR-TB Referral Centre, University College Hospital, Ibadan, Nigeria between July 2010 and December 2014. Enrolled were 115 patients with MDR-TB, out of which 22 (19.13\%) had MDR-TB/HIV co-infection.

\section{Data collection}

Height $(\mathrm{m})$, body weight $(\mathrm{kg})$ and body mass index $(\mathrm{kg} /$ $\mathrm{m}^{2}$ ) were taken using standard methods. Serum levels of TSH, free T4 (fT4) and free T3 (fT3) were determined using ELISA (Biotek, USA). Assessment of thyroid function is part of the pre-treatment medical assessment usually carried out on patients referred to the MDR-TB Unit of the hospital and $0.4-4.0 \mathrm{IU} / \mathrm{ml}, 59-153 \mathrm{nmol} / \mathrm{L}$ and $0.56-1.88 \mathrm{ng} / \mathrm{ml}$ were considered as the reference ranges for TSH, T4 and T3 respectively.

\section{Statistical analysis}

The distribution of all the variables was assessed using histogram with normal curve. All the variables except TSH, fT4 and fT3 had Gaussian distribution. Depending on the Gaussian distribution, differences of variables between groups were assessed using the Student's t, Mann Whitney U and Fisher's exact test. Results are presented as mean \pm standard deviation or median (interquartile range). $\mathrm{P}$ values less than 0.05 were considered as statistically significant.

\section{Results}

Majority of the patients had normal thyroid profile. Five (4.35\%), $9(7.83 \%)$ and $2(1.74 \%)$ patients had sick euthyroid syndrome (normal TSH level with low T3 and/ or T4 level), subclinical hypothyroidism (high TSH with normal T3 and T4) and subclinical hyperthyroidism (low TSH with normal T3 and T4) respectively.

As shown in Table 1, the median level of TSH was slightly higher while the median levels of T3 and T4 were slightly lower in patients with MDR-TB/HIV co-infection compared with MDR-TB patients only. However, the differences in the medians were not statistically significant. Similarly, the mean body weight and BMI were similar between the 2 groups. 
Table 1: Demographic characteristics, thyroid stimulating hormone and thyroid hormones levels in MDR-TB patients with or without HIV infection

\begin{tabular}{llll}
\hline & $\begin{array}{l}\text { MDR-TB } \\
(\mathrm{n}=93)\end{array}$ & $\begin{array}{c}\text { MDR-TB/HIV } \\
(\mathrm{n}=22)\end{array}$ & $P$-values \\
\hline Age (years) & $35.44 \pm 11.07$ & $33.18 \pm 9.18$ & 0.377 \\
Height $(\mathrm{m})$ & $1.63 \pm 0.26$ & $1.66 \pm 0.11$ & 0.617 \\
Body weight $(\mathrm{kg})$ & $48.40 \pm 13.26$ & $50.27 \pm 8.75$ & 0.530 \\
BMI $\left(\mathrm{kg} / \mathrm{m}^{2}\right)$ & $16.95 \pm 4.91$ & $18.13 \pm 2.58$ & 0.276 \\
$\mathrm{TSH}(\mathrm{IU} / \mathrm{ml})$ & $1.85(1.13-3.48)$ & $1.90(1.38-2.48)$ & 0.822 \\
$\mathrm{fT}_{4}(\mathrm{nmol} / \mathrm{L})$ & $91.00(70.00-107.00)$ & $88.00(62.75-103.70)$ & 0.516 \\
$\mathrm{fT}_{3}(\mathrm{ng} / \mathrm{ml})$ & $1.15(0.75-1.60)$ & $1.12(0.69-1.65)$ & 0.797 \\
\hline
\end{tabular}

$\mathrm{BMI}=$ body mass index, $\mathrm{TSH}=$ thyroid stimulating hormone, $\mathrm{fT}_{4}=$ free thyroxine, $\mathrm{fT} 3=$ free triiodothyronine, values are presented in mean \pm standard deviation or median (interquartile range)

When all the patients were pooled and compared based on gender (males and females), it was observed that the median levels of TSH, T3 and T4 were similar between the 2 groups. However, male patients were found to be significantly older and had higher BMI than the female patients (Table 2).

Table 2: Demographic characteristics, thyroid stimulating hormone and thyroid hormones levels in male and female MDR-TB patients without HIV infection and MDR-TB patients with HIV infection

\begin{tabular}{llll}
\hline & Male $(\mathrm{n}=76)$ & Female $(\mathrm{n}=39)$ & $P$-value \\
\hline Age $($ years $)$ & $37.30 \pm 11.04$ & $30.54 \pm 8.64$ & $0.001^{*}$ \\
Height $(\mathrm{m})$ & $1.65 \pm 0.28$ & $1.61 \pm 0.10$ & 0.395 \\
Body weight $(\mathrm{kg})$ & $51.62 \pm 13.03$ & $43.33 \pm 9.37$ & $0.001^{*}$ \\
$\mathrm{BMI}\left(\mathrm{kg} / \mathrm{m}^{2}\right)$ & $17.44 \pm 5.12$ & $16.65 \pm 3.26$ & 0.385 \\
$\mathrm{TSH}(\mathrm{IU} / \mathrm{ml})$ & $1.80(1.20-3.40)$ & $1.90(1.20-3.50)$ & 0.908 \\
$\mathrm{fT}_{4}(\mathrm{nmol} / \mathrm{L})$ & $87.00(67.10-101.50)$ & $93.00(70.00-112.00)$ & 0.116 \\
$\mathrm{fT}_{3}(\mathrm{ng} / \mathrm{ml})$ & $1.00(0.75-1.75)$ & $1.20(0.73-1.50)$ & 0.895 \\
\hline${ }^{*}$ Significant at $P<0.05, \mathrm{BMI}=\quad$ body mass index, TSH=thyroid stimulating \\
hormone, $\mathrm{fT}_{4}=$ free thyroxine, $\mathrm{fT}_{3}=$ free triiodothyronine, values are presented in mean \pm standard \\
deviation or median (interquartile range)
\end{tabular}

There was no difference in the median levels of TSH, infection were compared with male patients with MDRT3 and T4 when male patients with MDR-TB/HIV co- TB only (Table 3). 
Table 3: Demographic characteristics, thyroid stimulating hormone and thyroid hormones levels in male MDR-TB patients without HIV infection and male

MDR-TB patients with HIV infection

\begin{tabular}{llll}
\hline & $\begin{array}{l}\text { MDR-TB } \\
(\mathrm{n}=65)\end{array}$ & $\begin{array}{c}\text { MDR-TB/HIV } \\
(\mathrm{n}=11)\end{array}$ & $P$-value \\
\hline Age (years) & $33.83 \pm 8.44$ & $40.64 \pm 17.44$ & 0.231 \\
Height $(\mathrm{m})$ & $1.64 \pm 0.30$ & $1.72 \pm 0.04$ & 0.397 \\
Body weight $(\mathrm{kg})$ & $51.22 \pm 13.94$ & $53.91 \pm 5.28$ & 0.532 \\
BMI $\left(\mathrm{kg} / \mathrm{m}^{2}\right)$ & $17.30 \pm 5.48$ & $18.26 \pm 1.78$ & 0.570 \\
$\mathrm{TSH}(\mathrm{IU} / \mathrm{ml})$ & $1.80(1.18-3.83)$ & $2.10(1.60-2.40)$ & 0.823 \\
$\mathrm{fT}_{4}(\mathrm{nmol} / \mathrm{L})$ & $91.00(67.80-104.00)$ & $80.00(62.00-92.00)$ & 0.226 \\
$\mathrm{fT}_{3}(\mathrm{ng} / \mathrm{ml})$ & $1.00(0.75-1.83)$ & $1.14(0.65-1.70)$ & 0.688 \\
\hline
\end{tabular}

$\mathrm{BMI}=$ body mass index, $\mathrm{TSH}=$ thyroid stimulating hormone, $\mathrm{fT}_{4}=$ free thyroxine, $\mathrm{fT}_{3}=$ free triiodothyronine, values are presented in mean \pm standard deviation or median (interquartile range)

Similarly, the median levels of TSH, T3 and T4 were simi- and female patients with MDR-TB only (Table 4). lar in female patients with MDR-TB/HIV co-infection

Table 4: Demographic characteristics, thyroid stimulating hormone and thyroid hormones levels in female MDR-TB patients without HIV infection and female MDR-TB patients with HIV infection

\begin{tabular}{|c|c|c|c|}
\hline & $\begin{array}{l}\text { MDR-TB } \\
(n=28)\end{array}$ & $\begin{array}{l}\text { MDR-TB/HIV } \\
(\mathrm{n}=11)\end{array}$ & $P$-valu \\
\hline Age (years) & $35.04 \pm 12.26$ & $36.27 \pm 10.17$ & 0.769 \\
\hline Height(m) & $1.62 \pm 0.09$ & $1.60 \pm 0.13$ & 0.737 \\
\hline Body weight (kg) & $42.04 \pm 8.88$ & $46.64 \pm 10.19$ & 0.171 \\
\hline BMI $\left(\mathrm{kg} / \mathrm{m}^{2}\right)$ & $16.12 \pm 3.15$ & $18.00 \pm 3.28$ & 0.106 \\
\hline TSH (IU/ml) & $2.35(1.10-3.53)$ & $1.70(1.25-3.75)$ & 0.955 \\
\hline $\mathrm{fT}_{4}(\mathrm{nmol} / \mathrm{L})$ & $92.00(69.50-112.00)$ & $101.00(63.50-115.00)$ & 0.985 \\
\hline $\mathrm{fT}_{3}(\mathrm{ng} / \mathrm{ml})$ & $1.20(0.71-1.50)$ & $1.10(0.79-1.45)$ & 0.806 \\
\hline
\end{tabular}

$\mathrm{BMI}=$ body mass index, $\mathrm{TSH}=$ thyroid stimulating hormone, $\mathrm{fT}_{4}=$ free thyroxine, $\mathrm{fT}_{3}=$ free triiodothyronine, values are presented in mean \pm standard deviation or median (interquartile range) 
In Table 5, there was no significant association between HIV status and levels of TSH, T3 and T4.

Table 5: Association between MDR-TB/HIV co-infection, thyroid stimulating hormone and thyroid hormones in MDR-TB patients without HIV infection and MDR-TB patients with HIV infection

HIV
Yes
No
$\mathrm{N}$
$\mathrm{X}^{2}$
P-value

\begin{tabular}{|c|c|c|c|c|c|}
\hline \multicolumn{6}{|l|}{ TSH } \\
\hline Below reference range & $1(4.54 \%)$ & $1(1.08 \%)$ & 2 & 1.257 & 0.533 \\
\hline Within reference range & $17(77.27 \%)$ & $75(80.65 \%)$ & 92 & & \\
\hline Above reference range & $4(18.18 \%)$ & $17(18.28 \%)$ & 21 & & \\
\hline \multicolumn{6}{|l|}{$\mathrm{fT}_{3}$} \\
\hline Below reference range & $2(9.09 \%)$ & $4(4.30 \%)$ & 6 & 1.227 & 0.540 \\
\hline Within reference range & $16(72.73 \%)$ & $65(69.89 \%)$ & 81 & & \\
\hline Above reference range & $4(18.18 \%)$ & $24(25.81 \%)$ & 28 & & \\
\hline \multicolumn{6}{|l|}{$\underline{\mathrm{fT}}_{4}$} \\
\hline Below reference range & $4(18.18 \%)$ & $9(9.68 \%)$ & 13 & 1.863 & 0.394 \\
\hline Within reference range & $16(72.73 \%)$ & $79(84.95 \%)$ & 95 & & \\
\hline Above reference range & $2(9.09 \%)$ & $5(5.38 \%)$ & 7 & & \\
\hline
\end{tabular}

\section{Discussion}

The need for detection of thyroid disease in patients with MDR-TB cannot be under-estimated since reports have shown that subclinical hypothyroidism increases the risk of depression and reduces adherence to MDR-TB and HIV treatment ${ }^{16,17}$.

An independent association between chronic illnesses such as tuberculosis and thyroid disease has been reported $^{18,19}$. This might explain the observed SES, subclinical hypothyroidism and subclinical hyperthyroidism in our patients.

Reports have shown that HIV and TB infections cause alteration in thyroid function ${ }^{5,6}$. In this study, there was no significant difference in the median levels of thyroid stimulating hormone and thyroid hormones in patients with MDR-TB only and those with MDR-TB/HIV coinfection. This observation suggests that MDR-TB/HIV co-infection and MDR-TB infection have similar effects son thyroid function.
Modongo and Zetola ${ }^{20}$ reported that there is an association between male gender and the development of hypothyroidism in patients with MDR-TB on treatment. The median levels of thyroid stimulating hormone and thyroid hormones were similar between the male and female patients. Our observation shows that the effect of the illness on thyroid stimulating hormone and thyroid hormones levels might not be gender specific. However, male MDR-TB patients were observed to be older and with higher body weight than female patients. Comparing the male patients with MDR-TB only with male patients with MDR-TB/HIV co-infection, there was no significant difference in the median levels of thyroid stimulating hormone and thyroid hormones. A similar pattern was also observed when female patients with MDR-TB only were compared with female patients with MDR-TB/HIV co-infection. These observations further support our earlier observation that the effect of the illnesses on the thyroid function might not be gender specific. 
The observed lack of association between HIV status and thyroid stimulating hormone/thyroid hormones levels is in line with our observed non-significant difference in the median levels of thyroid stimulating hormone and thyroid hormones in patients with MDR-TB only and patients with MDR-TB/HIV co-infection. This observation shows that the presence of HIV infection does not seem to alter the thyroid function in MDR-TB patients before the commencement of MDR-TB drugs.

It could be concluded from this study that patients with MDR-TB/HIV co-infection have similar thyroid function compared with patients having MDR-TB without $\mathrm{HIV}$ infection before the commencement of MDR-TB drugs. However, the presence of SES and subclinical thyroid dysfunction in some of the patients indicates the need to assess thyroid function in MDR-TB patients with or without HIV infection before commencing MDRTB therapy as it could identify patients that might benefit from appropriate clinical intervention with a view to preventing aggravation of the thyroid disease during the course of the MDR-TB therapy.

\section{Conflict of Interest}

All authors have no conflict of interest to declare

\section{References}

1. Sharma SK, Mohan A. Multidrug-resistance tuberculosis: a menace that threatens to destabilize tuberculosis control. Chest 2006; 130 (1): 261-272. doi: 10.1378/ chest.130.1.261

2. World Health Organization (WHO) (2012) Global Tuberculosis Report 2012. (WHO/HTM/TB/2012.6). Geneva.

3. Caminero JA, Sotgiu G, Zumla A, Migliori GB. Best drug treatment for multidrug-resistant and extensively drug-resistant tuberculosis. Lancet Infect Dis 2010; 10:621629. doi: 10.1016/S1473-3099(10)70139-0.

4. Andries A, Isaakidis P, Das M, Khan S, Paryani R, Desai $C$ et al. High rate of hypothyroidism in multidrugresistant tuberculosis patients co-infected with HIV in Mumbai, India. PLoS One 2013; 8 (10):78313.PubMed e doi: 10.1371/journal.pone.0078313.

5. Sajid KM, Parveen R, Sabih DE, Mahmood R. Thyroid function in pulmonary tuberculosis. J Coll Physicians Surg Pak 2006; 16 (10): 633-636. PMID 17007749
6. Hoffman CJ, Brown TT. Thyroid Function Abnormalities in HIV-Infected Patients. Clin Infect Dis 2007; 45 (4): 488-494. doi: 10.1086/519978

7. Camacho PM, DwarKanathan AA. Sick euthyroid syndrome. What do we do when thyroid function tests are abnormal in critically ill patients? Postgrad Med 1999; 105 (4): 215-219.doi:10.3810/pgm.1999.04.694

8. Aatif S, Qamar R, Ahmed I, Imran K. Sick euthyroid syndrome: Thyroid function abnormalities in patients with non-thyroid illness. JLUMHS2008; 7 (2): 83-86.

9. Arbex MA, Varella MCL, Siqueira HR, Mello FAF. Antituberculosis drugs: Drug interactions, adverse effects, and use in special situations. Part 2: Second-line drugs. J Bras Pneumol. 2010; 36 (5):641-656.http://dx.doi. org/10.1590/S1806-37132010000500017

10. Maldonado LS, Murata GH, Hershman JM, Braunstein GD. Do thyroid function test independently predict the survival in the critically ill? Thyroid 1992; 2 (2): 119 -123. doi:10.1089/thy.1992.2.119.

11. Curry FJ. Drug-Resistant Tuberculosis: A Survival Guide for Clinicians, second Edition. 2008.

12. World Health Organization (WHO). Guidelines for the Programmatic Management of Drug-Resistant Tuberculosis Emergency Update (WHO/HTM/ TB/2008.402). Geneva. 2008.

13. Isaakidis P, Varghese B, Mansoor H, Cox HS, Ladomirska J, Saranchuk Pet al. Adverse events among HIV/MDR-TB co-infected patients receiving antiretroviral and second line anti-TB treatment in Mumbai, India. PLoS One 2012; 7 (7): e40781. doi: 10.1371/journal. pone.0040781.

14. Grappin M, Piroth L, Verges B, Sgro C, Mack G, Buisson $\mathrm{M}$ et al.Increased prevalence of subclinical hypothyroidism in HIV patients treated with highly active antiretroviral therapy. AIDS 2000; 14 (8): 1070-1072. PMID: 10853996

15. Beltran S, Lescure FX, Desailloud R, Douadi Y, Smail A, El Esper I et al.Increased Prevalence of Hypothyroidism among Human Immunodeficiency Virus-Infected Patients: A Need for Screening. Clin Infect Dis 2003; 37 (4): 579-583. doi: $10.1086 / 376626$

16. Yaqoob A. Subclinical hypothyroidism and its consequences. J Public Health Biol Sciences 2012; 1 (2): 53-60.

17. Do HM, Dunne MP, Kato M, Pham CV, Nguyen KV. Factors associated with suboptimal adherence to antiretroviral therapy in Viet Nam: a cross-sectional study using 
audio computer-assisted self interview (ACASI). BMC Infect Dis 2013; 13 (1): 154 PubMed . doi: 10.1186/14712334-13-154.

18. Chow CC, Mak TW, Chan CH, Cockram CS. Euthyroid sick syndrome in pulmonary tuberculosis before and after treatment. Ann Clin Biochem 1995; 32 (Pt 4): 385-391. doi: 10.1177/000456329503200406.
19. Jacobs TQ, Ross A. Adverse effects profile of multidrug-resistant tuberculosis treatment in a South African outpatient clinic. S Afr Fam Pract 2012; 54 (6): 531-539. 20. Modongo C, Zetola NM. Prevalence of hypothyroidism among MDR-TB patients in Botswana. Int $J$ Tuberc Lung Dis 2012; 16 (11): 1561-1562.doi: 10.5588/ ijtld.12.0403. 